\title{
Profil Pemecahan Masalah Matematika Siswa SMP Pangudi LUHUR SALATIGA DITINJAU DARI BERPIKIR KRITIS
}

\section{Mathematics Problem Solving Profile of Pangudi luhur Salatiga Junior High SCHOOL STUDENTS VIEWED FROM CRITICAL THINKING}

\author{
Anita Sri Mahardiningrum ${ }^{1}$ dan Novisita Ratu ${ }^{2}$ \\ 1 Program Studi Pendidikan Matematika, Universitas Kristen Satya Wacana \\ Jl. Diponegoro No. 52-60 Sidorejo, Salatiga, Jawa Tengah, Indonesia \\ 202014032@student.uksw.edu \\ 2Program Studi Pendidikan Matematika, Universitas Kristen Satya Wacana \\ Jl. Diponegoro No. 52-60 Sidorejo, Salatiga, Jawa Tengah, Indonesia \\ novisita.ratu@staff,uksw.edu
}

\begin{abstract}
Abstrak
Penelitian ini bertujuan untuk mendeskripsikan langkah-langkah penyelesaian yang ditempuh siswa dalam menyelesaikan masalah matematika berdasarkan tahapan Polya pada siswa SMP ditinjau dari berpikir kritis FRISCO (Fokus, Reason, Inference, Situasion, Clarity, and Overview). Jenis penelitian ini adalah penelitian deskriptif kualitatif. Teknik pengambilan subjek menggunakan purposive sampling dan diperoleh 3 subjek yang diambil dari siswa SMP Pangudi Luhur Salatiga dengan kategori berkemampuan tinggi, sedang dan rendah. Hasil penelitian menunjukkan bahwa profil pemecahan masalah subjek pada tahap: (1) Memahami masalah, subjek kategori tinggi dan sedang mampu menentukan apa yang diketahui dan ditanyakan dengan tepat serta memenuhi kriteria berpikir kritis FRISCO, sedangkan subjek kategori rendah belum mampu (2) Menyusun rencana pemecahan masalah, subjek kategori tinggi dan sedang mampu menentukan keterkaitan antara informasi serta memenuhi kriteria FRISCO, sedangkan subjek kategori rendah tidak memenuhi kriteria; (3) Melaksanakan rencana pemecahan, subjek kategori tinggi dan sedang mampu menggunakan langkah-langkah melaksanakan rencana, serta memenuhi kriteria berpikir kritis FRISCO, kategori rendah tidak memenuhi kriteria berpikir kritis Kata Kunci: pemecahan masalah tahapan Polya, berpikir kritis FRISCO.
\end{abstract}

\begin{abstract}
This research is aims to describe steps of how junior high school students solve the math problems based on Polya Steps, this research is viewed from FRISCO (Focus, Reason, Inference, Situation, Clarity and Overview) critical thinking. This is a descriptive qualitative research. Subjects sampling method used is Purposive Sampling and three subjects taken are from Pangudi Luhur Salatiga Junior High School students which were divided into diferent categories; high, medium, and low proficiency in Math. The results of the research show that: on step (1) Understanding Problem, subjects on high and medium categories could analyze what was asked correctly and could fulfill FRISCO critical thinking criterias, while, subject on low category could not. (2) Developing Plans to Solve the Problem, subjects on high and medium categories could decide interconection of informations and also could fulfill FRISCO critical thinking criterias, meanwhile, subject on low category could not. (3) Do the Plans to Solve the Problem, subjects on high and medium categories could follow the steps in the plans to solve the problems correctly and also could fulfill FRISCO critical thinking criterias, while, subject on low category could not follow the steps correctly, unable to answer the questions and also unable to fulfill critical thinking criterias.

Keyword: Polya Problem Solving, FRISCO Critical Thinking.
\end{abstract}




\section{Pendahuluan}

Matematika adalah suatu bidang ilmu yang berfungsi sebagai alat pikir, berkomunikasi, alat untuk memecahkan berbagai persoalan praktis, yang unsurunsurnya logis dan intuisi, analisis dan kontruksi, generalitas dan individualitas, serta mempunyai cabang-cabang antara lain aritmatika, aljabar, geometri dan analisis (Uno, 2008:129). Dalam memahami ilmu matematika, sering menghadapi masalah-masalah yang nyata jika kita kaitkan pada masalah-masalah yang ada dihadapan para pembelajarnya. Pada pembelajaran matematika masalah merupakan bagian yang sangat penting sehingga siswa dapat semakin maju dan berkembang dalam proses berpikirnya.

Pemecahan masalah merupakan salah satu kemampuan yang harus ditanamkan sejak dini karena akan sangat membantu manusia dalam menyelesaikan permasalahan dalam kehidupan seharihari. Sumarmo (Hulukarti, 2014:18) menyatakan bahwa pemecahan masalah merupakan kegiatan menyelesaikan soal cerita, menyelesaikan soal yang tidak rutin, mengaplikasikan matematika dalam kehidupan sehari-hari atau keadaan lain, dan membuktikan atau menciptakan atau menguji konjektur. Bahri (2009) menyatakan bahwa salah satu konsep matematika yang memerlukan penguasaan yang baik dalam pemecahan masalah adalah materi Sistem Persamaan Linear Dua Variabel (SPLDV). Sumarmo (Hulukati, 2014:18) menyatakan bahwa pemecahan masalah merupakan kegiatan menyelesaikan soal cerita, menyelesaikan soal yang tidak rutin, mengaplikasikan matematika dalam kehidupan sehari-hari atau keadaan lain, dan membuktikan atau menciptakan atau menguji konjektur. Salah satu strategi yang dapat digunakan dalam pemecahan masalah pembelajaran matematika adalah menggunakan strategi pemecahan masalah model Polya. Menurut George Polya (1971) untuk mempermudah memahami dan menyelesaikan suatu masalah, terlebih dahulu masalah tersebut disusun menjadi masalah-masalah sederhana, lalu dianalisis (mencari semua kemungkinan langkahlangkah yang akan ditempuh), kemudian dilanjutkan dengan sintesis (memeriksa kebenaran setiap langkah yang dilakukan). Pada tingkatan masalah tertentu, langkahlangkah Polya dapat disederhanakan menjadi empat langkah yaitu (1) memahami masalah, (2) membuat rencana penyelesaian, (3) melaksanakan rencana dan (4) melihat kembali.

Dalam memperoleh jawaban untuk memecahkan masalah matematika siswa harus berpikir agar mampu memahami konsep-konsep secara tepat ketika siswa harus mencari jawaban dari berbagai soal matematika. Dengan demikian siswa harus dilatih agar memiliki kemampuan berpikir kritis. Berpikir kritis adalah berpikir secara beralasan dan reflektif dengan menekankan pembuatan keputusan tentang apa yang harus dipercayai atau dilakukan (Hassoubah, 2004:87). Dalam berpikir kritis terdapat 6 kriteria (yang disingkat FRISCO) meliputi: (1) fokus, (2) 
reason, (3) inference, (4) situasion, (5) clarity, and (6) overview (Ennis, 1995:4). Enam elemen dasar dalam berpikir kritis ini merupakan elemen yang saling berkaitan dan bukan merupakan serangkaian langkah-langkah, tetapi lebih kepada daftaran yang digunakan untuk memastikan bahwa kita telah melakukan hal-hal yang sama. Desti (2011) menyatakan pada tahap memehami masalah, siswa harus mempunyai kemampuan interpretasi agar siswa memahami secara tepat masalah matematika yang diajukan kepadanya. Selain itu siswa juga harus mempunyai kemampuan evaluasi untuk mengevaluasi pemikirannya dalam memahami masalah. Kemampuan dalam pemecahan masalah ada pada ide menyusun rencana pemecahan, jadi pada tahap ini sangat diperlukan kemampuan berpikir kritis siswa. Pada tahap melaksanakan rencana pemecahan siswa akan menggali semua konsep dan prosedur yang telah dipelajari sehingga dapat memecahkan masalah dengan benar. Semua kemampuan berpikir kritis diperlukan disini terutama kemampuan eksplanasi. Pada tahap memahami masalah hingga tahap memeriksa kembali hasil pemecahan yang telah didapat semua kemampuan berpikir kritis sangat diperlukan untuk menguji apakah pemecahan masalah yang telah dilakukan sudah benar. Jadi dapat terlihat bahwa pembelajaran matematika dengan pemecahan masalah akan melatih siswa berpikir kritis. Berdasarkan penelitian yang dilakukan oleh dilakukan Dian (2013) dengan hasil penelitian menyimpulkan bahwa subjek kemampuan aljabar tinggi mengetahui fokus, alasan, situasi dan kejelasan dalam tiap-tiap tahap pemecahan masalah, subjek juga dapat menjelaskan inferensi pada setiap tahap pemecahan masalah Polya, kecuali pada tahap melaksanakan rencana, dan subjek kemampuan aljabar tinggi tidak memeriksa kembali pemikirannya hanya pada tahap memahami masalah saja. untuk subjek berkemampuan sedang pada langkah pemecahan masalah tidak melaksanakan langkah terakhir yaitu memeriksa kembali, sehingga profil berpikir kritisnya pada langkah ini tidak dapat dideskripsikan. Semantara untuk tiga tahap pemecahan masalah sebelumnya, subjek sedang mengetahui fokus, alasan, inferensi, dan kejelasan, namun tidak dapat menjelaskan situasi pada saat melaksanakan rencana. Sedangkan untuk subjek berkemampuan rendah mengtahui fokus, alasan dan memeriksa kembali pada setiap langkah pemecahan masalah Polya, namun inferensi hanya mampu menjelaskan pada tahap melaksanakan rencana dan memeriksa kembali, kejelasan hanya diberikan pada saat membuat rencana dan memeriksa kembali. Sementara situasi dijelaskan pada setiap langkah pemecahan masalah, kecuali pada langkah melaksanakan rencana. Berdasarkan Berdasarkan permasalahan diatas maka rumusan masalah dalam penelitian ini adalah "Bagaimana profil pemecahan masalah matematika siswa SMP Pangudi 
Luhur Salatiga ditinjau dari berpikir Kritis ?". Tujuan penelitian ini adalah untuk mendiskripsikan profil pemecahan masalah matematika siswa SMP Pangudi Luhur Salatiga ditinjau dari berpikir Kritis.

\section{Metode}

Jenis penelitian ini menggunakan penelitian kualitatif dengan pendekatan deskriptif. Subjek dalam penelitian ini adalah 3 siswa yang terdiri dari siswa berkemampuan tinggi yaitu S1, siswa berkemampuan sedang yaitu S2 dan siswa berkemampuan rendah yaitu S3. Teknik pengambilan subjek menggunakan teknik purposive sampling, dimana subjek dipilih berdasarkan kriteria tertentu. Ketiga subjek dipilih dari kelas IX SMP Pangudi Luhur Salatiga, dengan kategori kemampuan matematika. Metode untuk pengambilan data dalam penelitian ini adalah metode dokumentasi, metode tes dan metode wawancara. Dalam metode tes, tes yang digunakan berupa tes pemecahan masalah matematika yang terdiri dari 3 soal uraian sebagai berikut:

1. Alif 8 tahun lebih tua dari Dini. Jumlah umur Ali dan Dini 50 tahun. Berapa umur Ali dan Dini masingmasing?

2. Raka dan Bela berencana untuk membeli sebuah bola basket seharga Dua Ratus Lima Puluh Ribu Rupiah. Uang Bela, lima ribu kurangnya dari uang Raka. Dan mereka juga mengetahui bahwa satu setengah kali uang Raka sama dengan seratus lima puluh ribu rupiah lebihnya dari setengah uang Bela. Tentukan uang Bela sekarang! Apakah uang Raka dan Bela sudah cukup untuk membeli sebuah bola basket? Jelaskan.

3. Kenji memikirkan 2 bilangan. Jika bilangan pertama ditambah dengan dua kali bilangan kedua maka hasilnya 26. Jika bilangan kedua ditambah dengan 2 kali bilangan pertama maka hasilnya 10. Tentukanlah kedua bilangan tersebut.

Instrumen utama dalam penelitian ini adalah peneliti sendiri dan pedoman wawancara. Analisis data dalam penelitian ini meliputi reduksi data, penyajian data dan penarikan kesimpulan, sedangkan pengujian keabsahan data dalam penelitian ini menggunakan teknik triangulasi teknik dan waktu.

\section{Hasil dan Pembahasan}

Hasil penelitian menunjukkan bahwa tahap pemecahan masalah yang dilakukan subjek penelitian berdasarkan tahapan Polya (1) memahami masalah, membuat rencana penyelesaian, (3) melaksanakan rencana dan (4) melihat kembali, serta kriteria berpikir kritis pada materi sistem persamaan linear dua variabel. Subjek dalam penelitian ini adalah 3 siswa dengan kemampuan yang berbeda yaitu siswa berkemampuan tinggi (S1), siswa berkemampuan sedang (S2), dan siswa berkemampuan rendah (S3). Selanjutnya subjek tersebut diberi soal untuk dikerjakan dan wawancara. 
1. Siswa berkemampuan matematika tinggi (S1)

Tabel 1.

Tabel Kesimpulan S1

\begin{tabular}{|c|c|c|c|c|c|c|c|c|c|c|c|c|}
\hline \multirow{5}{*}{$\begin{array}{l}\text { Krite } \\
\text { ria } \\
\text { Berpi } \\
\text { kir } \\
\text { Kritis }\end{array}$} & \multicolumn{12}{|c|}{ S1 } \\
\hline & \multicolumn{12}{|c|}{ Butir Soal } \\
\hline & \multicolumn{4}{|c|}{1} & \multicolumn{4}{|c|}{2} & \multicolumn{4}{|c|}{3} \\
\hline & \multicolumn{4}{|c|}{$\begin{array}{c}\text { Tahapan } \\
\text { Polya }\end{array}$} & \multicolumn{4}{|c|}{$\begin{array}{c}\text { Tahapan } \\
\text { Polya }\end{array}$} & \multicolumn{4}{|c|}{$\begin{array}{c}\text { Tahapan } \\
\text { Polya }\end{array}$} \\
\hline & 1 & 2 & 3 & 4 & 1 & 2 & 3 & 4 & 1 & 2 & 3 & 4 \\
\hline$F$ & v & v & V & $\sqrt{ }$ & V & V & $v$ & v & $v$ & $v$ & $\mathrm{v}$ & $\begin{array}{lll}v & & -1\end{array}$ \\
\hline$R$ & $\bar{v}$ & & & & $\mathrm{v}$ & & & & $\mathrm{v}$ & & & \\
\hline I & & & & & & & & & & & & \\
\hline $\mathrm{S}$ & v & v & V & V & v & v & $\sqrt{ }$ & V & 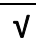 & $\mathrm{V}$ & $\mathrm{v}$ & $\sqrt{ }$ \\
\hline C & $\mathrm{v}$ & $v$ & $\mathrm{v}$ & $v$ & $v$ & $\mathrm{v}$ & $v$ & 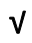 & 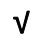 & 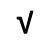 & $v$ & $\mathrm{v}$ \\
\hline 0 & $\sqrt{ }$ & $v$ & $\mathrm{v}$ & $\sqrt{ }$ & $\sqrt{ }$ & $\sqrt{ }$ & v & $\sqrt{ }$ & $\begin{array}{lll} & \end{array}$ & $\mathrm{v}$ & $\sqrt{ }$ & $\mathrm{v}$ \\
\hline
\end{tabular}

Pada soal nomor 1, 2, dan 3, S1 telah memahami masalah yang diberikan dengan baik. S1 mampu menentukan dan menuliskan apa yang diketahui dan apa yang ditanyakan dari soal dengan benar dan lengkap. Kemudian pada tahap memahami masalah ini S1 menjelaskan kriteria berpikir kritis focus, reason, situation, clarity, dan overview, dimana S1 dapat membangun makna tentang masalah apa yang akan dipecahkan (focus), memberikan alasan terhadap hasil rumusan masalah yang telah dibangun (reason), mengetahui apa yang diketahui dan apa yang ditanyakan dari soal (situation), menjelaskan istilah-istilah yang digunakan (clarity), dan mengecek kembali (overview). Namun belum mampu memenuhi kriteria inference karena subjek belum mampu menarik kesimpulan yang logis dalam melakukan pemecahan masalah. Kemudian untuk tahap membuat rencana dan melaksanakan rencana untuk soal nomor 1 dan 3, S1 mampu membuat rencana dan melakukan rencana dengan baik, yaitu untuk soal nomor satu S1 merencanakan untuk mencari umur Dini dulu dengan menggunakan penjumlahan umur Ali dan Dini yaitu 50 tahun. Kemudian melakukan rencana dengan baik dan benar pula hingga menemukan jawaban bahwa umur Dini 21 tahun dan umur Ali 29 tahun. Dan untuk soal nomor tiga S1 juga telah melalui tahap membuat rencana dan melakukan rencana dengan baik dan benar. Untuk soal nomor tiga, S1 membuat rencana pemecahan masalah dengan cara eliminasi yaitu dengan mengeliminasi salah satu variabelnya. Pada tahap melakukan rencana S1 melalui dengan baik, meskipun sempat mengalami kebingungan namun S1 dapat melakukan dengan benar. S1 juga menjelaskan kriteria berpikir kritis focus, situation, clarity, dan overview, dimana S1 dapat memutuskan strategi dan menerapkan strategi terpilih (focus), mengetahui halhal penting yang perlu diperhatikan dalam membuat rencana dan hal-hal penting yang perlu diperhatikan dalam langkahlangkah penerapan strategi (situation), dapat menjelaskan istilah-istilah yang digunakan (clarity), serta mengecek apakah strategi masuk akal untuk memecahkan masalah yang dihadapi dan mengecek langkah-langkah penerapan strategi yang telah dilakukan apakah masuk akal untuk memecahkan masalah (overview). Namun untuk soal nomor 2, pada tahap merencanakan pemecahan masalah dan melaksanakan rencana pemecahan masalah S1 mengalami sedikit 
kesalahan. Pada tahap merencanakan pemecahan masalah S1 sudah memisalkan $\mathrm{R}=$ uang Raka dan $\mathrm{B}=$ uang Bela. Kemudian mencari uang Raka dengan menggunakan dari soal yang diketahui itu, bahwa satu setengah kali uang Raka sama dengan Rp150.000,00 lebihnya dari setengah uang Bela serta dapat membuat model matematika dengan benar. Akan tetapi pada tahap melaksanakan rencana S1 mengalami kesalahan, yang seharusnya tadi diketahui bahwa satu setengah kali uang Raka sama dengan Rp150.000,00 dari setengah uang Bela, sehingga satu setengah kali uang Raka sama dengan Rp150.000,00 ditambah satu setengah dikali Uang Raka dikurangi Rp5.000,00. Dan seharusnya dalam setengah uang Raka dikurangi Rp5.000,00 harusnya dihitung terlebih dahulu, namun S1 tidak menghitung terlebih dahulu. Serta pada soal nomor dua, S1 mengetahui kriteria berpikir kritis focus, situation, clarity, dan overview, dimana S1 dapat memutuskan strategi dan menerapkan strategi terpilih (focus), mengetahui hal-hal penting yang perlu diperhatiakan dalam membuat rencana dan hal-hal penting yang perlu diperhatikan dalam langkah-langkah penerapan strategi (situation), dapat menjelaskan istilah-istilah yang digunakan (clarity), serta mengecek apakah strategi masuk akal untuk memecahkan masalah yang dihadapi dan mengecek langkahlangkah penerapan strategi yang telah dilakukan apakah masuk akal untuk memecahkan masalah (overview). Pada soal nomor 1, 2, dan 3 tahap terakhir yaitu tahap memeriksa kembali S1 telah memalui tahap ini dengan baik dan benar, S1 mengetahui keputusan untuk memeriksa jawaban yang telah diperoleh (focus), mengetahui hal-hal penting yang perlu diperhatikan dalam memeriksa jawaban yang diperoleh (situation), menjelaskan istilah-istilah yang digunakan (clarity), dan mengecek semua hal yang telah dilakukan (overview), sehingga S1 dapat mengetahui bahwa jawaban pada nomor 2 ada yang salah. Namun dalam setiap tahap pemecahan masalah S1 belum mampu memenuhi kriteria inference karena subjek belum mampu menarik kesimpulan yang logis dalam melakukan pemecahan masalah.

2. Siswa berkemampuan matematika sedang (S2)

Tabel 2.

Tabel Kesimpulan S2

\begin{tabular}{|c|c|c|c|c|c|c|c|c|c|}
\hline \multirow{5}{*}{$\begin{array}{l}\text { Krite } \\
\text { ria } \\
\text { Berpi } \\
\text { kir } \\
\text { Kritis }\end{array}$} & \multicolumn{8}{|c|}{ S2 } & \\
\hline & \multicolumn{9}{|c|}{ Butir Soal } \\
\hline & \multicolumn{4}{|c|}{1} & \multicolumn{2}{|c|}{2} & \multicolumn{3}{|c|}{3} \\
\hline & \multicolumn{4}{|c|}{$\begin{array}{c}\text { Tahapan } \\
\text { Polya }\end{array}$} & \multicolumn{2}{|c|}{$\begin{array}{c}\text { Tahapan } \\
\text { Polya } \\
\end{array}$} & \multicolumn{3}{|c|}{$\begin{array}{c}\text { Tahapan } \\
\text { Polya }\end{array}$} \\
\hline & 1 & 2 & 3 & 4 & 1 & 2 & & 12 & 4 \\
\hline $\mathrm{F}$ & $\mathrm{v}$ & $\sqrt{ }$ & 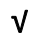 & $\mathrm{V}$ & V & v & & $\mathrm{V} \quad \mathrm{V}$ & $\sqrt{ }$ \\
\hline \multicolumn{10}{|l|}{$\mathrm{R}$} \\
\hline \multicolumn{10}{|l|}{ I } \\
\hline$S$ & V & V & & V & V & $\sqrt{ }$ & & $\sqrt{ } \quad \mathrm{V}$ & V \\
\hline$C$ & $\sqrt{ }$ & $\sqrt{ }$ & $\sqrt{ }$ & $\sqrt{ }$ & $\sqrt{ }$ & $\sqrt{ }$ & & $\begin{array}{ll}\mathrm{V} & \mathrm{V}\end{array}$ & $\sqrt{ }$ \\
\hline 0 & $v$ & $\mathrm{~V}$ & V & $\sqrt{ }$ & $V$ & $\sqrt{ }$ & & & $\sqrt{ }$ \\
\hline
\end{tabular}

Pada soal nomor 1, 2, dan 3, S2 telah memahami masalah yang diberikan dengan baik. S2 mampu menentukan dan menuliskan apa yang diketahui dan apa yang ditanyakan dari soal dengan benar dan lengkap. Kemudian pada tahap memahami masalah ini S2 menjelaskan 
kriteria berpikir kritis focus, reason, situation, clarity, dan overview, dimana S2 dapat membangun makna tentang masalah apa yang akan dipecahkan (focus), memberikan alasan terhadap hasil rumusan masalah yang telah dibangun (reason), mengetahui apa yang diketahui dan apa yang ditanyakan dari soal (situation), menjelaskan istilah-istilah yang digunakan (clarity), dan mengecek kembali (overview). Kemudian untuk tahap membuat rencana dan melaksanakan rencana untuk soal nomor satu, S2 mampu membuat rencana dan melakukan rencana dengan baik, yaitu untuk soal nomor satu S2 merencanakan untuk memisalkan terlebih dahulu, namun S2 tidak menuliskan didalam lembar kerja. Setelah memisalkan, S2 mensubstitusikan sampai menemukan jawaban. Kemudian melakukan rencana dengan baik dan benar pula hingga menemukan jawaban bahwa umur Dini 21 tahun dan umur Ali 29 tahun. S2 juga menjelaskan kriteria berpikir kritis focus, situation, dan overview, dimana S2 dapat memutuskan strategi dan menerapkan strategi terpilih (focus), mengetahui hal-hal penting yang perlu diperhatiakan dalam membuat rencana dan hal-hal penting yang perlu diperhatikan dalam langkah-langkah penerapan strategi (situation), menjelaskan istilah-istilah yang digunakan (clarity), serta mengecek apakah strategi masuk akal untuk memecahkan masalah yang dihadapi dan mengecek langkahlangkah penerapan strategi yang telah dilakukan apakah masuk akal untuk memecahkan masalah (overview). Untuk soal nomor 2, pada tahap merencanakan pemecahan masalah dan melaksanakan rencana pemecahan masalah S2 merencanakan untuk mencari uangnya Raka terlebih dahulu, setelah ketemu uangnya Raka S2 mencari uang Bela, kemudian S2 menjumlahkan dan mengurangkan untuk mencari dengan harga bola basket. Akan tetapi pada tahap melaksanakan rencana S2 mengalami sedikit kesalahan, pada saat mencari uang Raka, namun pada langkah selanjutnya S2 menuliskan dengan benar. Serta pada soal nomor dua ini S2 mengetahui kriteria berpikir kritis focus, situation, clarity, dan overview, dimana S2 dapat memutuskan strategi dan menerapkan strategi terpilih (focus), mengetahui hal-hal penting yang perlu diperhatikan dalam membuat rencana dan hal-hal penting yang perlu diperhatikan dalam langkah-langkah penerapan strategi (situation) yaitu dengan melihat keterkaitan antara hal yang diketahui dengan hal yang ditanyakan, dapat menjelaskan istilahistilah yang digunakan (clarity) yaitu $R$ sebagai uang Raka dan untuk uang Bela tidak dimisalkan, serta mengecek apakah strategi masuk akal untuk memecahkan masalah yang dihadapi dan mengecek langkah-langkah penerapan strategi yang telah dilakukan apakah masuk akal untuk memecahkan masalah (overview). Kemudian untuk soal nomor 3, pada tahap merencanakan pemecahan masalah dan tahap melaksanakan masalah S2 mampu merencanakan pemecahan dengan baik, 
yaitu dengan cara eliminasi. Namun pada saaat menyamakan konstanta agar dapat dieliminasi S2 melakukan kesalahan tidak mengalikan 2 disalah satu persamaan. Jadi dalam tahap melaksanakan masalah S2 menemukan jawaban yang salah. Serta S2 mengetahui kriteria berpikir kritis dapat memutuskan strategi dan menerapkan strategi terpilih (focus), mengetahui halhal penting yang perlu diperhatiakan dalam membuat rencana dan hal-hal penting yang perlu diperhatikan dalam langkah-langkah penerapan strategi (situation) yaitu dengan melihat keterkaitan antara hal yang diketahui dengan hal yang ditanyakan, dapat menjelaskan istilah-istilah yang digunakan (clarity) yaitu $x$ adalah bilangan pertama dan $y$ adalah bilangan kedua. Pada soal nomor 1, 2, dan 3 tahap terakhir yaitu tahap memeriksa kembali S2 telah melalui tahap ini dengan baik dan benar, S2 mengetahui keputusan untuk memeriksa jawaban yang telah diperoleh (focus), mengetahui hal-hal penting yang perlu diperhatikan dalam memeriksa jawaban yang diperoleh (situation), menjelaskan istilah-istilah yang digunakan (clarity), dan mengecek semua hal yang telah dilakukan (overview), sehingga S2 dapat mengetahui bahwa jawaban pada nomor 3 ada yang salah karena kurang mengalikan 2. Namun S3 belum bisa memenuhi kriteria reason dan inference pada setiap tahap pemecahan masalah karena subjek belum mampu memberikan alasan yang logis serta menarik kesimpulan yang masuk akal dalam melakukan pemecahan masalah.
3. Siswa berkemampuan matematika rendah (S3)

Tabel 3.

Tabel Kesimpulan S3

\begin{tabular}{|c|c|c|c|c|c|c|c|c|c|c|c|c|}
\hline \multirow{5}{*}{$\begin{array}{l}\text { Krite } \\
\text { ria } \\
\text { Berpi } \\
\text { kir } \\
\text { Kritis }\end{array}$} & \multicolumn{12}{|c|}{ S3 } \\
\hline & \multicolumn{12}{|c|}{ Butir Soal } \\
\hline & \multicolumn{4}{|c|}{1} & \multicolumn{3}{|c|}{2} & \multicolumn{5}{|c|}{3} \\
\hline & \multicolumn{4}{|c|}{$\begin{array}{c}\text { Tahapan } \\
\text { Polya }\end{array}$} & \multicolumn{4}{|c|}{$\begin{array}{c}\text { Tahapan } \\
\text { Polya }\end{array}$} & \multicolumn{4}{|c|}{$\begin{array}{c}\text { Tahapan } \\
\text { Polya }\end{array}$} \\
\hline & 1 & 2 & 3 & 4 & 1 & 2 & 3 & 4 & 1 & 2 & 3 & 4 \\
\hline $\mathrm{F}$ & $\mathrm{V}$ & $\sqrt{ }$ & & & $\mathrm{V}$ & & & & V & & & \\
\hline \multicolumn{13}{|l|}{$R$} \\
\hline \multicolumn{13}{|l|}{1} \\
\hline$S$ & $\sqrt{ }$ & & & & $\mathrm{V}$ & & & & $\mathrm{V}$ & & & \\
\hline$C$ & $\mathrm{~V}$ & $\sqrt{ }$ & & & $\mathrm{V}$ & & & & $\mathrm{V}$ & & & \\
\hline 0 & $\sqrt{ }$ & & & & $\sqrt{ }$ & & & & V & & & \\
\hline
\end{tabular}

Pada soal nomor 1, 2, dan 3, S3 belum memahami masalah yang diberikan dengan baik. S3 mampu menentukan dan menuliskan apa yang diketahui dan apa yang ditanyakan dari soal, namun tidak lengkap. Kemudian pada tahap memahami masalah, S3 menjelaskan kriteria berpikir kritis focus, situation, clarity, dimana S3 dapat membangun makna tentang masalah apa yang akan dipecahkan (focus), mengetahui apa yang diketahui dan apa yang ditanyakan dari soal (situation), menjelaskan istilah-istilah yang digunakan (clarity). Kemudian untuk tahap membuat rencana dan melaksanakan rencana untuk soal nomor 1, S3 mampu membuat rencana yaitu dengan memisalkan dan kemudian mensubstitusi, akan tetapi dalam melaksanakan rencana S3 belum mampu melakukannya dengan baik, karena S3 telihat masih bingung. Sehingga pada tahap merencanakan pemecahan dan melaksanakan rencana S3 hanya masuk 
dalam kriteria berpikir kritis focus yaitu dapat memutuskan strategi dan menerapkan strategi namun salah, dan kriteria clarity yaitu menjelaskan istilahistilah yang digunakan. Kemudian untuk soal nomor dua, pada tahap merencanakan pemecahan dan melaksanakan rencana S3 belum mampu memahami apa yang ingin direncanakan dan dilakukan untuk menyelesaikan masalah. Sehingga untuk nomor dua pada tahap merencanakan masalah, melaksanakan masalah, dan S3 juga tidak memeriksa kembali jawaban nomor dua, jadi S3 tidak masuk dalam kriteria berpikir kritis FRISCO. Selanjutnya untuk soal nomor tiga, pada tahap merencanakan pemecahan masalah dan melaksanakan rencana S3 belum mampu merencanakan pemecahan dengan tepat, sehingga dalam melakukan pemecahan masalah S3 tidak mampu menemukan jawaban dengan benar. Dalam hal ini S3 belum memenuhi dalam kriteria berpikir FRISCO. Kemudian untuk tahap terakhir yaitu memeriksa kembali jawaban S3 melakukan pengecekan kembali dengan meneliti jawaban, namun S3 tidak memahami maksud soal jadi S3 merasa bahwa jawaban sudah benar.

\section{Penutup}

Berdasarkan pembahasan di atas dapat disimpulkan bahwa siswa berkemampuan matematika tinggi, dapat memahami masalah, merencanakan mapemecahan, melakukan rencana pemecahan, dan memeriksa kembali pemecahan. Dan siswa berkemampuan matematika tinggi dapat memenuhi kriteria berpikir kritis focus, reason, situation, clarity, dan overview, namun belum bisa memenuhi kriteria inference karena subjek belum mampu menarik kesimpulan yang logis dalam melakukan pemecahan masalah. Namun dalam melakukan rencana pemecahan masalah melakukan kesalahan dalam menghitung pada salah satu soal yang diselesaikan. Siswa berkemampuan matematika sedang dapat memahami masalah, merencanakan pemecahan, melakukan rencana pemecahan, dan memeriksa kembali pemecahan. Dan siswa berkemampuan matematika tinggi dapat memenuhi kriteria berpikir kritis focus, situation, clarity, dan overview, namun belum bisa memenuhi kriteria reason dan inference karena subjek belum mampu memberikan alasan yang logis serta menarik kesimpulan yang masuk akal dalam melakukan pemecahan masalah. Dalam melaksanakan rencana pemecahan masalah subjek melakukan kesalahan dalam menghitung disalah satu soal yang diselesaikan. Siswa berkemampuan matematika rendah tidak dapat melakukan tahapan pemecahan masalah dengan baik, dan hanya memenuhi kriteria berpikir kritis focus, clarity pada satu soal. Karena subjek belum mampu memahami masalah.

Berdasarkan hasil penelitian ini, peneliti mengemukakan beberapa saran sebagai berikut:

Bagi guru, hendaknya mempertimbangkan hasil penelitian yang telah dilakukan untuk menciptakan suatu 
model pembelajaran yang efektif bagi peningkatan kemampuan pemecahan masalah siswa dan mengasah kemampuan berpikir kritis, memberikan banyak latihan soal pemecahan masalah agar siswa terbiasa mengerjakan soal pemecahan masalah.

Bagi siswa, hendaknya memperbanyak intensitas latihan soal pemecahan maslah agar terbiasa dalam mengerjakan soal. Bagi siswa yang masih mengalami kesulitan dalam menyelesaikan soal hendaknya memperbanyak latihan soal dengan menuliskan apa yang diketahui, apa yang ditanya, merencanakan penyelesaian, dan memeriksa kembali agar lebih mudah dalam memahami dan menyelesaikan soal.

Bagi penelitian lain, dapat menggunakan penelitian ini sebagai dasar dalam melakukan penelitian tindakan kelas ataupun penelitian lainnya.

\section{Daftar Pustaka}

Bekti, Tri. 2014. Profil Pemecahan Masalah Berbentuk Open-Ended Berdasarkan Tahapan Polya Pada Siswa SMP Negeri 5 Salatiga Dalam Materi Lingkaran. Salatiga:Universitas Kristen Satya Wacana.

Moleong, Lexy.J. 2000. Metodologi Penelitian Kualitatif. Bandung: PT. Rosdakarya.

Dewanti, SS. 2011. Mengembangkan Kemampuan Berpikir Kristis Mahasiswa Pendidikan Matematika Sebagai Calon Pendidik Karaketer Bangsa Melalui Pemecahan Masalah. http://publikasiilmiah.ums.ac.id.
Diakses pada tanggal 29-08-2016, pukul 08.00 WIB

Ennis, Robert H. (1992). Critical Thinking: What Is It? http://www.ed.uiuc.edu/eps/PES-

Yearbook/92 docs/ENNIS.HTM

Diakses tanggal 4 februari 2011. Ennis, Robert H. (1995). Critical Thinking. New Jersey: Prentice-Hall. Novita R, Dian \& Rahmawati, Ana. (2014).

Profil Berpikir Kritis siswa Dalam Memecahkan Masalah Matematika Ditinaju Dari Kecerdasan Majemuk Sebagai Upaya dasar menentukan Strategi pemebelajaran.

http://Ippm.unmas.ac.id/wpcontent/uploads/2014/06/5-diannovita-rohmatin-KL1.pdf.

\section{Riwayat Hidup PenUlis}

Anita Sri Mahardiningrum, S.Pd.

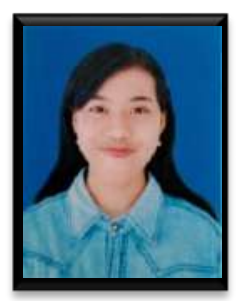

Lahir di Semarang, 4 September 1996 Studi S1 Pendidikan Matematika Universitas Kristen Satya Wacana, Salatiga, 2018. Infromasi publikasi terbaik yang pernah dilakukan berupa jurnal skripsi.

Novisita Ratu, S.Pd. M.Pd.

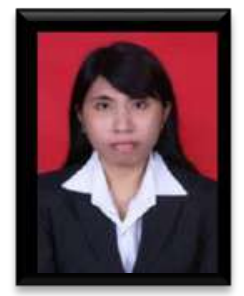

Lahir di Kupang, tanggal 07 november 1981. Dosen Program Pendidikan Matematika Universitas Kristen Satya Wacana, Salatiga. S1 Matematika Universitas Sanata Dharma Yogyakarta, S2 Manajemen Pendidikan Universitas Kristen Satya Wacana Salatiga. Presenter di AMD (Asian Mathematics Conference), dan mendapat Short Course dari Australia Award Fellowship di Sun Shine Coast University Australia. 